\title{
Effect of Level and Type of Mushroom on Performance, Blood Parameters and Natural Coccidiosis Infection in Floor-Reared Broilers
}

\author{
W. L. Willis ${ }^{1, *}$, D. C. Wall ${ }^{1}$, O. S. Isikhuemhen ${ }^{2}$, J. N. Jackson ${ }^{1}$, S. Ibrahim ${ }^{3}$, S. L. Hurley ${ }^{1}$, and \\ F. Anike ${ }^{1}$
}

${ }^{I}$ Department of Animal Sciences, North Carolina A\&T State University, Greensboro, North Carolina 27411, USA

${ }^{2}$ Department of Natural Resources and Environmental Design, North Carolina A\&T State University, Greensboro, North Carolina 27411, USA

${ }^{3}$ Department of Family and Consumer Sciences, North Carolina A\&T State University, Greensboro, North Carolina 27411, USA

\begin{abstract}
An experiment was conducted to evaluate the feeding of four medicinal mushrooms via fungus myceliated grain (FMG) at three levels on production performance, blood parameters and natural coccidiosis oocyst excretion in floor reared broiler chickens. Three hundred day-old female broiler chickens were weighed and randomly assigned to nine different treatment groups. Each group was replicated three times with 10 birds per replicate pen. The four mushrooms utilized were Shiitake (Lentinus edodes), Reishi (Ganoderma lucidum), Oyster (Pleurotus ostreatus) and Cordyceps (Cordycepss inensis). Each mushroom was supplemented at a 5 and $10 \%$ inclusion level into a basal meal ration, and compared to a control ration containing no mushrooms. Body weights were assessed on days 28 and 49. Bursa weights, Eimeria oocyst counts, blood differential percentages and mortality rates were measured at 49 days of age. Eimeria oocyst counts, blood differential percentages and both bursa and body weights differed significantly $(\mathrm{P} \leq 0.05)$ between treatment groups. Treatment 8 (Oyster 5\%) produced the highest average body weight at $3.21 \mathrm{~kg}$, while treatment 5 (Cordyceps $10 \%$ ) produced the lowest at $2.33 \mathrm{~kg}$. A higher oocyst count and increased heterophil percentage was observed in treatment 6 (Reishi 5\%). There were some basic trends in the patterns of heterophil and lymphocyte percentage elevation in treatment 3 (Shiitake 10\%). The results from this experiment demonstrate the ability of certain mushrooms to influence body weight of broiler chickens and show some immune enhancement via the bursa of Fabricius.
\end{abstract}

Keywords: Broiler chickens, health, medicinal mushrooms, performance.

\section{INTRODUCTION}

Consumers of poultry have become extremely sensitive about drugs utilized in production to protect poultry against infectious disease. This concern is due in part to the drugresistant strains of many microorganisms occurring in the production environment. Therefore, a need arises for new ways of keeping birds healthy and free of disease in an intensive, confined rearing environment. As a result, nonchemical methods to protect our poultry without drug usage are being researched with great interest.

Medicinal mushrooms are an increasing focus of research because of their potential to enhance the immune responses in chickens and their antiparasitic activities [1]. Cell walls of mushrooms contain a high number of polysaccharides known as beta-glucans that are derived from the fruiting bodies of mushrooms [2]. Both in-vitro and in-vivo studies demonstrate that 1-3 and 1-6 glucans promote immune enhancement, thereby supporting the innate immune system

*Address correspondence to this author at the Department of Animal Sciences, North Carolina A\&T State University, Greensboro, North Carolina 27411, USA; Tel: (336) 334-7786; Fax: (336) 334-7288;

E-mail:willisw@ncat.edu against bacterial, viral, fungal and parasitic infections. These effects are achieved by activating macrophages, T-helper and natural killer cells that also involve the differentiation and proliferation of T-lymphocytes [3]. Guo et al. [4, 5], demonstrated the protective effects of mushrooms and their extracts against Eimeria tenella infection.In a recent study conducted by Willis et al. [6], four different medicinal mushrooms (Shiitake, Cordyceps, Reishi, and Oyster) were utilized for their potential immunomodulating properties in Eimeria challenged broiler chickens. These specific mushrooms were chosen for their extensive immunotherapeutic backgrounds in multiple scientific observations involving both animal and human related studies. In this particular trial by Willis et al., they evaluated the effects of feeding these four different medicinal mushrooms, both singularly and combined, via FMG to broilers challenged with Eimeria and reared in battery brooder cages. The major findings in this study demonstrated that broilers fed shiitake via FMG were superior in their performance and Eimeria protection as opposed to broilers supplemented with Reishi, Oyster and Cordyceps or a combination of all four. Cordyceps was found to cause some depression in broiler body weights whether or not the bird was experimentally challenged with Eimeria at the time, however it also showed 
Table 1. Composition of Basal Diets

\begin{tabular}{|c|c|c|c|}
\hline Ingredients & & Amount & \\
\hline & Starter & Grower & Finisher \\
\hline Corn & 1167 & 1324 & 1410 \\
\hline Corn micro-flush & 19.94 & 20.73 & 20.30 \\
\hline Limestone fine & 19.42 & 20.40 & 21.37 \\
\hline Lysine $(78.5 \%)$ & 0.01 & 1.26 & 4.27 \\
\hline Methionine (99\%) & 3.80 & 2.67 & 2.01 \\
\hline Threonine & 1.06 & 0.02 & 1.58 \\
\hline Salt & 10.00 & 10.00 & 10.00 \\
\hline PX NCSU Br Mineral (TM90) & 4.00 & 4.00 & 4.00 \\
\hline Poultry fat (Miter) & 10.00 & 10.00 & 10.00 \\
\hline Total batch weight & 2000 & 2000 & 2000 \\
\hline
\end{tabular}

the ability to significantly reduce oocyst shedding. Both the Oyster and Reishi FMG supplemented broilers proved to be relatively consistent in all other measured parameters. In another study, Dalloul et al., [7] investigated the immunepotentiating effect of a mushroom lectin extracted from Fomitellafraxiena on poultry cell-mediated immunity and protection against coccidiosis. Their results from utilizing the mushroom lectin included effective growth promotion and immune stimulation in poultry with coccidiosis. In many cultures throughout the years, there have been numerous reports of a plethora of positive effects that mushrooms have had on human health [8-10]. Yet very little research or reports are available about the effects on animals, particularly poultry. However, FMG as a dietary supplement for chickens, has been observed to have the potential to support strong immune functions, growth, and general health [4]. Our publications and those of others make it imperative that we contribute to the small body of scientific information with additional studies and reports for poultry. The present study therefore investigates: growth performance, blood differentials, oocyst shedding and the general health of broiler chicks fed different medicinal mushrooms via FMG.

\section{MATERIALS AND METHODOLOGY}

Three hundred $(\mathrm{n}=300)$, day-old, female broiler chickens (Ross x Ross) were obtained from a commercial hatchery. The chicks were weighed and randomly distributed into 9 different treatment groups, replicated 3 times with 10 chicks per pen as follows: 1) Control-no FMG, 2) FMG Shiitake $5 \%$, 3) FMG Shiitake 10\%, 4) FMG Cordyceps5\%, 5) FMG Cordyceps10\%, 6) FMG Reishi 5\%, 7) FMG Reishi 10\%, 8) FMG Oyster 5\% and 9) FMG Oyster 10\%. All chicks were vaccinated against Marek's disease, infectious bronchitis and Newcastle disease. Each treatment group was housed and maintained within a 27 floor pen system, with each pen (1.2 $\mathrm{m}^{2}$ ) containing one drinker and one hanging feeder. The bedding utilized was composed of recycled wood shavings. A basal meal ration free of any medications was utilized for the inclusion supplement of FMG and fed ad libitum. Blood samples for differential counts, fecal samples for oocyst counts, mortality tallies and both body and bursa weights were collected and evaluated at 49 days of age.

\section{MUSHROOM CULTIVATION AND BASAL DIET}

Shiitake, Cordyceps, Reishi, and Oyster mushrooms were cultivated by the Mushroom Biology and Fungal Biotechnology Laboratory at North Carolina A\&T State University. Sterile sorghum grain wasseparately inoculated with the selected fungi at $25^{\circ} \mathrm{C}$ for two weeks before use [11]. The resulting myceliated grain was processed by airdrying at about $25^{\circ} \mathrm{C}$ for approximately six hours and ground into a powder that was used to supplement the basal rations in the experimental trials. The basal diet composition is shown in (Table 1). The four different mushrooms were put into the basal diet at 0,5 and 10 percent levels, mixed thoroughly and placed into hanging tubular feeders in the respective treatment pens.

\section{BLOOD DIFFERENTIAL CELL COUNT}

Blood samples were collected at day 49 from the jugular veins of broilers during processing and were secured in tubes coated with lithium heparin anticoagulant. Samples were placed on ice and transported to the laboratory where blood smeared slides were immediately prepared, fixed and stained with HEMA3. A total of 100 cells per slide were counted and the results were expressed as percentages of heterophils, lymphocytes, monocytes, eosinophils, and basophils.

\section{EIMERIA FECAL ANALYSIS}

Fecal samples were collected at day 49 from 4 birds within each treatment that had been placed in battery brooder cages prior to collection. The samples were transported to 
Table 2. Body Weights of Broilers on Days 1, 28, and 49

\begin{tabular}{|c|c|c|c|c|}
\hline No. & Treatments & Day 1 & Day 28 & Day 49 \\
\hline \hline 1. & Control (no FMG) & $0.05 \pm 0.00 \mathrm{a}$ & $1.36 \pm 0.02 \mathrm{a}$ & $2.92 \pm 0.10 \mathrm{ab}$ \\
\hline 2. & Shiitake 5\% FMG & $0.05 \pm 0.00 \mathrm{a}$ & $1.31 \pm 0.07 \mathrm{a}$ & $2.97 \pm 0.09 \mathrm{ab}$ \\
\hline 3. & Shiitake 10\% FMG & $0.05 \pm 0.00 \mathrm{a}$ & $1.28 \pm 0.01 \mathrm{ab}$ & $2.65 \pm 0.03 \mathrm{bc}$ \\
\hline 4. & Cordyceps5\% FMG & $0.05 \pm 0.00 \mathrm{a}$ & $1.17 \pm 0.048 \mathrm{~b}$ & $2.68 \pm 0.09 \mathrm{bc}$ \\
\hline 5. & Cordyceps10\% FMG & $0.05 \pm 0.00 \mathrm{a}$ & $1.00 \pm 0.07 \mathrm{c}$ & $2.33 \pm 0.23 \mathrm{c}$ \\
\hline 6. & Reishi 5\% FMG & $0.05 \pm 0.00 \mathrm{a}$ & $1.32 \pm 0.01 \mathrm{a}$ & $2.92 \pm 0.03 \mathrm{ab}$ \\
\hline 7. & Reishi 10\% FMG & $0.05 \pm 0.00 \mathrm{a}$ & $1.32 \pm 0.02 \mathrm{a}$ & $2.92 \pm 0.03 \mathrm{ab}$ \\
\hline 8. & Oyster 5\% FMG & $0.05 \pm 0.00 \mathrm{a}$ & $1.31 \pm 0.00 \mathrm{a}$ & $3.21 \pm 0.19 \mathrm{a}$ \\
\hline 9. & Oyster $10 \%$ FMG & $0.05 \pm 0.00 \mathrm{a}$ & $1.32 \pm 0.04 \mathrm{a}$ & $2.92 \pm 0.03 \mathrm{ab}$ \\
\hline
\end{tabular}

Note. FGM = fungus-myceliated grain. Mean values down the column having the same alphabets are not significantly different at $p \leq 0.05$ according to Duncan's Multiple Range tests.

Table 3. Live Weight, Bursa Weight Including Absolute and Relative Weight of Birds on Day 49

\begin{tabular}{|c|c|c|c|c|}
\hline No. & Treatment & Live Wt. & $\begin{array}{c}\text { Bursa Wt. } \\
\text { (Absolute) }\end{array}$ & $\begin{array}{c}\text { Bursa Wt. } \\
\text { (Relative) }\end{array}$ \\
\hline \hline 1. & Control (No FMG) & $2.99 \pm 0.103 \mathrm{a}$ & $3.44 \pm 0.336 \mathrm{ab}$ & $0.257 \pm 0.148 \mathrm{ab}$ \\
\hline 2. & Shiitake 5\% FMG & $2.97 \pm 0.081 \mathrm{ab}$ & $2.83 \pm 0.255 \mathrm{ab}$ & $0.213 \pm 0.081 \mathrm{~b}$ \\
\hline 3. & Shiitake 10\% FMG & $2.66 \pm 0.064 \mathrm{~cd}$ & $3.06 \pm 0.207 \mathrm{ab}$ & $0.227 \pm 0.079 \mathrm{ab}$ \\
\hline 4. & Cordyceps 5\% FMG & $2.58 \pm 0.098 \mathrm{~d}$ & $3.03 \pm 0.217 \mathrm{ab}$ & $0.222 \pm 0.076 \mathrm{ab}$ \\
\hline 5. & Cordyceps10\% FMG & $2.36 \pm 0.010 \mathrm{e}$ & $2.58 \pm 0.219 \mathrm{~b}$ & $0.255 \pm 0.095 \mathrm{ab}$ \\
\hline 6. & Reishi 5\% FMG & $2.73 \pm 0.069 \mathrm{bcd}$ & $3.49 \pm 0.327 \mathrm{a}$ & $0.273 \pm 0.111 \mathrm{a}$ \\
\hline 7. & Reishi 10\% FMG & $2.88 \pm 0.053 \mathrm{abc}$ & $3.28 \pm 0.314 \mathrm{ab}$ & $0.232 \pm 0.105 \mathrm{ab}$ \\
\hline 8. & Oyster 5\% FMG & $2.91 \pm 0.050 \mathrm{ab}$ & $2.80 \pm 0.281 \mathrm{ab}$ & $0.259 \pm 0.102 \mathrm{ab}$ \\
\hline 9. & Oyster 10\% FMG & $2.99 \pm 0.052 \mathrm{a}$ & $3.20 \pm 0.263 \mathrm{ab}$ & $0.258 \pm 0.092 \mathrm{ab}$ \\
\hline
\end{tabular}

Note. Mean values down the column having the same alphabets are not significantly different at $p \leq 0.05$ according to the Duncan's Multiple Range tests.

the laboratory where 2 grams of feces per tube was measured out onto a small scale and the placed into a clear, sterile container in which $30 \mathrm{ml}$ of sodium nitrate was conjugated. The mixture of solution and fecal matter was strained through cheese cloth and transferred to the chambers of a McMaster's slide. Samples were read on a 10x10 magnification using a compound microscope. The total number of eggs counted within the two chambers was multiplied by 50 , giving the eggs per gram for each sample [12].

\section{RESULTS AND DISCUSSION}

\section{Body Weights}

There were significant differences $(\mathrm{P} \leq 0.05)$ in body weights between treatment groups at 28 and 49 days of age (Table 2). Supplementing broiler diets with FMG had a significant $(\mathrm{P} \leq 0.05)$ effect on the body weight of broiler chicks at 28 and 49 days of age compared with chicks fed the control diet. In addition, the type of mushroom and the levels of supplementation had a significant effect on broiler body weights. At day 28, broilers belonging to experimental treatment groups 2 (Shiitake 5\%), 3 (Shiitake 10\%), 6 (Reishi 5\%), 7 (Reishi 10\%), 8 (Oyster 5\%), and 9 (Oyster $10 \%$ ) showed no significant differences between each other and did not differ significantly when compared to the control treatment 1 (Control-No FMG), but did exhibit significantly higher weight differences than treatments 4 (Cordyceps5\%) and 5 (Cordyceps10\%). These treatments displayed the lowest body weights, which may indicate that this important performance parameter is adversely affected. In a published study by Willis et al. [13], some gender differences in response to Shiitake mushroom extracts were observed. At day 49 , broilers belonging to treatment 5 (Cordyceps $10 \%$ ) continued to show the lowest significant body weights when compared to other treatment groups. Broilers belonging to treatment 8 (Oyster 5\%) had the highest body weight, but did not differ significantly from neither the control nor the treatment groups 2 (Shiitake 5\%), 6 (Reishi 5\%), 7 (Reishi $10 \%$ ), and 9 (Oyster 10\%). These results indicated that the birds responded differently to the mushroom type and level of inclusion in regards to body weight. The mushroom composition in relation to physiochemical properties and the phenolic content, including polysaccharide fractions, could be the basis for the observed results as well as sugar composition, molecular weights, and structures [14]. The literature does not contain many studies in this area; therefore, more research is needed. It is clear that one must be selective in the type of mushroom utilized in order to avoid reduction in body weight performance.

\section{Bursa Weights}

Treatment 6 (Reishi 5\%) revealed the highest relative numerical weight that did not differ significantly from the control-No FMG (treatment 1) and treatments 3 (Shiitake 10\%), 4 (Cordyceps5\%), 5 (Cordyceps10\%), 7 (Reishi 10\%), 8 (Oyster 5\%), and 9 (Oyster 10\%), but did differ significantly from treatment 2 (Shiitake 5\%) as depicted in (Table 3). Generally, the higher bursa weight reflects better health status, 
Table 4. Eimeria Counts of Broilers on Day 49

\begin{tabular}{|c|c|c|}
\hline No. & Treatment & Oocysts Count \\
\hline \hline 1. & Control (No FMG) & $2325.00 \pm 875.71 \mathrm{~b}$ \\
\hline 2. & Shiitake 5\% FMG & $2044.00 \pm 422.38 \mathrm{~b}$ \\
\hline 3. & Shiitake $10 \%$ FMG & $7925.00 \pm 3530.37 \mathrm{~b}$ \\
\hline 4. & Cordyceps5\% FMG & $775.00 \pm 176.19 \mathrm{~b}$ \\
\hline 5. & Cordyceps10\% FMG & $1662.50 \pm 216.39 \mathrm{~b}$ \\
\hline 6. & Reishi 5\% FMG & $52200.00 \pm 11566.71 \mathrm{a}$ \\
\hline 7. & Reishi $10 \%$ FMG & $2112.50 \pm 1022.53 \mathrm{~b}$ \\
\hline 8. & Oyster 5\% FMG & $812.50 \pm 296.77 \mathrm{~b}$ \\
\hline 9. & Oyster $10 \%$ FMG & $10362.50 \pm 5100.59 \mathrm{~b}$ \\
\hline
\end{tabular}

Note. Mean values down the column having the same alphabets are not significantly different at $p<0.05$ according to Duncan's Multiple Range tests.

Table 5. Differential Cell Count of Chicken Blood at Day 49

\begin{tabular}{|c|c|c|c|c|c|}
\hline Treatment & Heterophils & Lymphocytes & Monocytes & Eosinophils & Basophils \\
\hline \hline 1 & $27 \pm 1.1547 \mathrm{ab}$ & $42.33 \pm 0.882 \mathrm{a}$ & $17.66 \pm 2.403 \mathrm{ab}$ & $9 \pm 1.154 \mathrm{ab}$ & $4 \pm 0.577 \mathrm{a}$ \\
\hline 2 & $28.33 \pm 0.882 \mathrm{ab}$ & $43.33 \pm 1.453 \mathrm{a}$ & $18 \pm 0.577 \mathrm{ab}$ & $9.66 \pm 0.333 \mathrm{ab}$ & $1.33 \pm 0.333 \mathrm{~b}$ \\
\hline 3 & $32 \pm 2.082 \mathrm{a}$ & $41.66 \pm 1.202 \mathrm{a}$ & $15 \pm 1.527 \mathrm{~b}$ & $10.33 \pm 1.768 \mathrm{ab}$ & $1 \pm 0.577 \mathrm{~b}$ \\
\hline 4 & $27 \pm 1.154 \mathrm{ab}$ & $44.33 \pm 0.882 \mathrm{a}$ & $16.66 \pm 1.202 \mathrm{ab}$ & $11.33 \pm 0.333 \mathrm{ab}$ & $.66 \pm 0.667 \mathrm{~b}$ \\
\hline 5 & $30 \pm 0.577 \mathrm{ab}$ & $40 \pm 1.155 \mathrm{ab}$ & $18.33 \pm 0.882 \mathrm{ab}$ & $11 \pm 1.155 \mathrm{ab}$ & $.66 \pm 0.333 \mathrm{~b}$ \\
\hline 6 & $31 \pm 1.528 \mathrm{ab}$ & $35.66 \pm 1.768 \mathrm{~b}$ & $18.66 \pm 0.882 \mathrm{ab}$ & $13.66 \pm 0.882 \mathrm{a}$ & $1 \pm 0.577 \mathrm{~b}$ \\
\hline 7 & $30 \pm 1.527 \mathrm{ab}$ & $39.33 \pm 4.255 \mathrm{ab}$ & $16.66 \pm 0.881 \mathrm{ab}$ & $13.66 \pm 2.603 \mathrm{a}$ & $.33 \pm 0.333 \mathrm{~b}$ \\
\hline 8 & $26 \pm 2.645 \mathrm{~b}$ & $41 \pm 1 \mathrm{ab}$ & $20 \pm 0.577 \mathrm{a}$ & $12.33 \pm 2.728 \mathrm{ab}$ & $.66 \pm 0.667 \mathrm{~b}$ \\
\hline 9 & $29.33 \pm 0.882 \mathrm{ab}$ & $44.66 \pm 0.882 \mathrm{a}$ & $17.66 \pm 0.667 \mathrm{a}$ & $8 \pm 1 \mathrm{~b}$ & $.33 \pm 0.333 \mathrm{~b}$ \\
\hline
\end{tabular}

Note. Mean values down the column having the same alphabets are not significantly different at $p \leq 0.05$ according to Duncan's Multiple Range tests.

possibly indicating very little immunosuppression. This data appears to indicate that the health of birds consuming the Cordycepsmushroom was not impaired even though body weights were severely depressed with the inclusion of this type of mushroom. Moreover, in unpublished data at this location, the antibody titer (IgA) was higher for Cordycepsthan other mushroom types. Lymphoid organ weights reflect the body's ability to provide lymphoid cells during an immune response. Immunosuppressed or stressed birds usually have smaller lymphoid organs [15]. The bursa of Fabricius has an extremely vital role for which the birds' immune reactivity is conditioned and modified by morphologic and functional integrity of the immune system. The weight of the bursa in broilers also reflects the anatomical response to immune system alteration due to stress. The data collected and analyzed in this study, reflects and support a previous study [13] which indicated some measure of stress and/or lack of nutrients that were inadvertently exerted on both the female and male birds during the experiment. Furthermore, after additional research with this extract, it was concluded that birds were given too much for too long. These factors individually or combined could be responsible for the significant differences in the bursa weights recorded.

\section{Eimeria Oocyst Count}

There was one treatment that differed significantly $(\mathrm{P} \leq 0.05)$ from all others (Table 4). Treatment 6 (Reishi 5\%) had significantly more oocyst shed in the fecal droppings at
49 days of age than any other treatment. Treatments 4 (Cordyceps5\%) and 8 (Oyster 5\%) exhibited lower numerical trends in this natural coccidiosis infection when compared to other treatments. With natural infections, the response is very unpredictable because many rearing environmental factors, including moisture of the litter, can contribute to an increase or decrease in the population of Eimeria spp. In this study, broilers were housed on recycled wood shaving litter that had been dormant for about four weeks. The viability of oocysts decline rapidly in poultry litter regardless of the species. Viability is retained best in $40 \%$ moisture at $4^{\circ} \mathrm{C}$ [16]. In addition, the carryover from one flock to another depends on the survival of a few oocysts on arthropod vectors or dust. The inclusion level of mushroom type did not significantly influence the natural infection rate in this study, whereas in the study by Willis et al., [6] the inclusion level did influence the infection rate of Eimeria challenged broilers. As in previous unpublished work conducted by these researchers, data on natural infection varied each time in confinement rearing facilities and in pastured poultry environments. Therefore, the oocyst count results are, to some extent, inconclusive and more studies are needed to assess the effectiveness of mushrooms in improving coccidiosis protection naturally and experimentally.

\section{Differential Blood Cell Counts}

There were significant differences $(\mathrm{P} \leq 0.05)$ in blood differential counts between the control and experimental 
Table 6. Mortality Rate of Broilers Over 49-Day Period

\begin{tabular}{|c|l|c|c|c|}
\hline No. & \multicolumn{1}{|c|}{ Treatments } & \# No. of Birds Starting & \# No. of Birds Ending & Mortality Percent (No.) \\
\hline \hline 1. & Control (No FMG) & 30 & 30 & $0 \%$ \\
\hline 2. & Shiitake 5\% FMG & 30 & 28 & $7 \%(2)$ \\
\hline 3. & Shiitake 10\% FMG & 30 & 29 & $4 \%(1)$ \\
\hline 4. & Cordyceps5\% FMG & 30 & 30 & $4 \%(1)$ \\
\hline 5. & Cordyceps10\% FMG & 30 & 29 & $0 \%$ \\
\hline 6. & Reishi 5\% FMG & 30 & 30 & $0 \%$ \\
\hline 7. & Reishi 10\% FMG & 30 & 30 & 27 \\
\hline 8. & Oyster 5\% FMG & 30 & 28 & $70 \%(3)$ \\
\hline 9. & Oyster 10\% FMG & 30 & $27)$ \\
\hline
\end{tabular}

treatments at 49 days of age (Table 5). The birds in treatment 6 (Reishi 5\%) showed significantly reduced lymphocyte percentages, whereas, treatment 8 (Oyster 5\%) showed significantly reduced heterophils when compared to the control and treatment 3 (Shiitake 10\%), respectively. The significance of this difference is not known as this time. However, body weights were numerically higher than any other treatment and statistically higher than some other treatments at 49 days of age. In a study conducted by Willis et al., [11] results showed no dose response changes by feeding Shiitake FMG on heterophils and lymphocytes percentages. In most avian species, healthy birds have more lymphocytes than heterophils in circulation, which influences the $\mathrm{H}: \mathrm{L}$ ratio [17]. Both lymphocytes and heterophils are believed to be functional in phagocytosis. The numbers of heterophils increase during moderately stressful conditions and consequently the heterophil: lymphocyte ratio can be utilized to detect the presence of physiological stress [18]. Since there was no disease challenge in this experiment, heterophil counts were not expected to show an increase. An immunological challenge can raise the number of heterophils in an immune response very early because they are the first line of response in birds [19]. Normally, the heterophil value increases between 1 and $7 \%$ outside the normal value of $10-25 \%$, and since the control was about $27 \%$, no infection was observed. In a diseased state, the number of reactive lymphocytes increase, as the normal lymphocyte value of chickens is between 65$80 \%$ [20]. Lymphocyte values in chickens decrease between 29 and $40 \%$ outside the normal value. Therefore, the data indicates no significant deviation in reduction from the control group except for treatment 6 (Reishi 5\%), possibly indicating a small infection from the coccidiosis which showed the highest significantly Eimeria count of all treatments. Moreover, treatment 6 (Reishi 5\%) showed a numerical increase in heterophil percentage. Ogbe et al., [21] stated that fluctuations in hematological values of avian blood are a normal phenomenon, and in most instances the variations in hematological values depend on the physiological state of the birds. Since the level of natural infection or number of oocysts was inconsistent in this study, the blood differential data did not make it clear whether mushroom type or level provided any protection against Eimeria challenges in relation to the heterophil:lymphocyte ratio. In another study conducted by Gadde et al., [22] no significant differences were found in the proportions of lymphocytes, heterophils, monocytes, basophils, or heterophil: lymphocyte ratio of infected and uninfected birds. There appeared to be some modulation of monocyte activity in treatment 3 (Shiitake 10\%), in relationship to innate and acquired immune responses. This observation builds on the work of Qureshi, [23] which indicated that various dietary, genetic and environmental manipulations can modulate the activity of monocytes.

\section{Mortality Rates}

The mortality percentages are shown in (Table 6). Mortality rates assessed during the duration of this experiment were relatively low with treatments 1 (ControlNo FMG), 4 (Cordyceps5\%), 6 (Reishi 5\%) and 7 (Reishi $10 \%$ ) having no mortalities. The higher rates were observed in treatment 8 (Oyster 5\%) with 10 percent (3/30) which appears very high percentage-wise but based on the small number of birds per treatment, it was at an acceptable level. Based on this performance data and others, it isnot believed that there was any correlation between treatment effect and broiler mortalities.

\section{CONCLUSIONS}

The results from this study indicate that different fungi and levels of their inclusion into the basal feed can impact production performance responses significantly and enhance the overall health of broiler chickens. It is concluded that there are ample advantages to using natural medicinal mushrooms as immunonutrition verses antibiotics to enhance health and production performance of broiler chickens. In previous research findings, it has been demonstrated that broilers experimentally challenged with Eimeria were more responsive to treatment with mushroom FMG than those who obtained a natural infection. Reduced performance was observed in birds fed Reishi and Oyster FMG supplemented diets compared with those fed diets supplemented with Shiitake FMG, however sufficient protection was observed against Eimeria infection. These application methods can be utilized simultaneously to manage parasitic diseases, increase weight gain, and boost the immune system. Finally, the fact that Cordycepsalone displayed lower body weights, one should not promote its use alone at any level of supplementation in broiler rations without further investigation. It is possible to supplement Cordycepsat lower levels and improve broiler weight while maintaining immune 
enhancement. In the future, it is important to further identify the active component of Cordyceps and elucidate its molecular mechanism that is responsible for its effect on body weights in broiler chickens because the protein percent of the fungal myceliated grain is comparable to the other mushroom types that were utilized in this study.

\section{CONFLICT OF INTEREST}

The authors confirm that this article content has no conflicts of interest.

\section{ACKNOWLEDGEMENTS}

This research was supported by National Institute of Food and Agriculture (NIFA) funding.

\section{REFERENCES}

[1] Borchers AT, Ed. Mushrooms, Tumors, and Immunity: 1999. Proceedings of the Society for Experimental Biology and Medicine. Soc Exper Biol Med 1999; 221(4): 281-93.

[2] Wasser SP. Current findings, future trends, and unsolved problems in studies of medicinal mushrooms. Appl Microbiol Biotechnol 2011; 89(5): 1323-32.

[3] Dalmo RA, Bøgwald J. B-glucans as conductors of immune symphonies. Fish Shellfish Immunol 2008; 25(4): 384-96.

[4] Guo FC, Kwakkel RP, Williams BA, et al. Effects of mushroom and herb polysaccharides on cellular and humoral immune responses of Eimeria tenella-infected chickens. Poult Sci 2004; 83(7): 1124-32.

[5] Guo FC, Kwakkel RP, Williams CB, Suo X, Li WK, Verstegen MW. Coccidiosis Immunization: effects of mushroom and herb polysaccharides on immune responses of chickens infected with eimeria tenella. Avian Dis 2005; 49(1): 70-3.

[6] Willis WL, Wall DC, Isikhuemhen OS, et al. Effect of different mushrooms fed to eimeria-challenged broilers on rearing performance. Int J Poult Sci 2012; 11(7): 433-7.

[7] Dalloul RA, Lillehoj HS, Lee JS, Lee SH, Chung KS. Immunopotentiating effect of a Fomitella fraxinea-derived lectin on chicken immunity and resistance to coccidiosis. Poult Sci 2006; 85(3): 446-51.
[8] Jong SC, Birmingham JM. Medicinal benefits of the mushroom Ganoderma. Adv Appl Microbiol 1992; 37: 101-34.

[9] Oei P. Benefits of mushrooms. $3^{\text {rd }}$ ed. Leiden: Backhuys 2003.

[10] Meschino JP. Reishi Mushroom Extract and Immune Support. Dyn Chiropractic 2002; 20(12): 1-8.

[11] Willis WL, Isikhuemhen OS, Ibrahim S, King K, Minor R, Ohimain EI. Effect of dietary fungus myceliated grain on broiler performance and enteric colonization with bifidobacteria and salmonella. Int J Poult Sci 2010; 9(1): 48-52.

[12] Hodgson JN. Coccidiosis: oocyst counting technique for coccidiostat evaluation. Exp Parasitol 1970; 28(1): 99-102.

[13] Willis WL, Isikhuemhen OS, Ibrahim SA. Performance assessment of broiler chickens given mushroom extract alone or in combination with probiotics. Poult Sci 2007; 86(9): 1856-60.

[14] Guo FC, Savelkoul HFJ, Kwakkel RP, Williams BA, Verstegena MWA. Immunoactive, medicinal properties of mushroom and herb polysaccharides and their potential use in chicken diets. World Poult Sci J 2003; 59(4): 427-40.

[15] Pope CR. Pathology of lymphoid organs with emphasis on immunosuppression. Vet Immunol Immunop 1991; 30(1): 31-44.

[16] Reyna PS, McDougald LR, Mathis GF. Survival of coccidia in poultry litter and reservoirs of infection. Avian Dis 1983; 27(2): 464-73.

[17] Campbell TW, Christine KE. Avian and Exotic Animal Hematology and Cytology. In: Avian and Exotic Animal Hematology and Cytology. USA: Wiley-Blackwell 2007; pp. 1034.

[18] Maxwell MH, Robertson GW. The avian basophilic leukocyte: A review. World Poultry Sci J 1995. 51(3): 307-25.

[19] Harmon BG. Avian heterophils in inflammation and disease resistance. Poult Sci 1998; 77(7): 972-7.

[20] Mitchell EB, Johns J. Avian hematology and related disorders. Vet Clin North Am Exot Anim Pract 2008; 11(3): 501-22.

[21] Ogbe AO, Atawodi SE, Abdu PA, Oguntayo BO, Noel D. Oral treatment of Eimeria tenella-infected broilers using aqueous extract of wild mushroom (Ganoderma sp): Effect on haematological parameters and histopathology lesions. Afr J Biotechnol 2010; 9: 8923-7.

[22] Gadde U, Chapman HD, Rathinam TR, Erf GF. Acquisition of immunity to the protozoan parasite Eimeria adenoeides in turkey poults and the peripheral blood leukocyte response to a primary infection. Poult Sci 2009; 88(11):2346-52.

[23] Qureshi MA. Role of macrophages in avian health and disease. Poult Sci 1998; 77(7):978-82. 